\title{
Optimalisasi Kemampuan Higher Order Thinking Skills Mahasiswa Semester Awal melalui Penggunaan Bahan Ajar Berbasis Berpikir Kritis
}

\author{
${ }^{1}$ Retno Andriyani, ${ }^{2}$ Nisvu Nanda Saputra \\ Pendidikan Matematika, FKIP, Universitas Muhammadiyah Tangerang \\ Email:2nisvunandasaputra@gmail.com
}

Article History:

Received: 12-11-2019; Received in Revised: 25-03-2020; Accepted: 30-03-2020

\begin{abstract}
The ability of critical thinking is part of Higher Order Thinking Skills (HOTS). To develop the ability of critical thinking is crucial to support the development of high-level thinking skills. The study aims to see the use of critical thinking-based teaching materials to optimize early semester student critical thinking skills in trigonometric courses. This research is a qualitative descriptive study, the subject of research is a student of early semester on trigonometric courses. The research subject amounted to 25 people. The results of the study that the use of the teaching materials critical thinking can increase the ability of the Higher Order Thinking student early semester that follows trigonometric courses.
\end{abstract}

Keywords: Critical Thinking; HOTS ; Optimization of Student Ablities.

\begin{abstract}
Abstrak
Kemampuan berpikir kritis merupakan bagian dari Higher Order Thinking Skills (HOTS). Pengembangan kemampuan berpikir kritis sangat penting untuk mendukung kesuksesan mahasiswa dalam melakukan HOTS. Penelitian ini bertujuan untuk melihat penggunaan bahan ajar berbasis berpikir kritis untuk mengoptimalkan HOTS mahasiswa semester awal pada mata kuliah trigonometri. Penelitian ini merupakan penelitian tindakan dengan subjek penelitian adalah mahasiswa semester awal pada mata kuliah trigonometri. Subjek penelitian berjumlah 25 orang. Hasil penelitian menunjukkan penggunaan bahan ajar berpikir kritis dapat mengoptimalkan kemampuan Higher Order Thinking Skill (HOTS) mahasiswa semester awal yang mengikuti mata kuliah trigonometri.
\end{abstract}

Kata Kunci: Berpikir Kritis; HOTS; Optimalisasi Kemampuan Mahasiswa. 


\section{Pendahuluan}

Program studi pendidikan matematika adalah program studi yang bertujuan untuk menghasilkan tenaga pendidik dan kependidikan yang berkompeten dibidangnya. Oleh sebab itu mahasiswa prodi pendidikan matematika tidak hanya diharapkan dapat menguasai konsep-konsep matematika melainkan juga dapat menguasai kemampuan matematis yang lainnya, seperti kemampuan komunikasi, pemecahan masalah, penalaran, berpikir kritis, berpikir kreatif serta masih banyak lagi yang lainnya. Salah satu tujuan utama dari penerapan kurikulum 2013 atau KKNI adalah mahasiswa harus dapat berpikir tingkat tinggi atau yang sering disebut dengan Higher Order Thinking Skills (HOTS). Oleh karena itu mahasiswa semester awal prodi pendidikan matematika harus dapat mengembangkan serta menguasai kemampuan HOTS.

Untuk mengembangakn kemampuan Higher Order Thinking Skills mahasiswa tidak hanya diperlukan model pengajaran yang tepat tetapi juga harus didukung oleh perangkat yang digunakan. Salah satu perangkat yang digunakan dalam perkulihan trigonometri adalah bahan ajar. Bahan ajar yang digunakan harus mengikuti karakteristik mahasiswa. Oleh karean itu karakteristik penyajian suatu bahan ajar akan sangat berperan penting dalam mencapai tujuan atau kemampuan yang akan dicapai. Bahan ajar adalah segala bentuk bahan yang digunakan oleh guru/instruktur dalam melaksanakan kegiatan didalam kelas. Bahan ajar yang digunakan dalam bentuk tertulis maupun yang tidak tertulis ${ }^{1}$. Bahan ajar disusun secara sistematik sehingga tercipta suasana yang memungkinkan mahasiswa untuk belajar ${ }^{2}$.

Manfaat pembelajaran dengan penerapan bahan ajar adalah: 1) meningkatkan motivasi peserta didik, karena tugas pelajaran dibatasi dengan jelas dan sesuai dengan kemampuan; 2) setelah dilakukan evaluasi, pendidik dan peserta didik mengetahui benar pada bahan ajar yang mana peserta didik telah berhasil dan pada bagian mana mereka belum berhasil; 3) peserta didik mencapai hasil sesuai dengan kemampuannya; 4) bahan pelajaran terbagi lebih merata dalam satu semester dan 5) pendidikan lebih berdaya guma, karena bahan pelajaran disusun menurut jenjang akademik ${ }^{3}$.

1 Dita Puja Lestari, "Pengembangan Bahan Ajar Matematika Dengan Pendekatan Scientific Untuk Meningkatkan Kemampuan Berpikir Kritis Matematis Siswa SMA Negeri 1 Bandar Pulau," AXIOM: Jurnal Pendidikan Dan Matematika 7, no. 2 (2018).

2 Sri Wahyuni, "Pengembangan Bahan Ajar IPA Untuk Meningkatkan Kemampuan Berpikir Kritis Siswa SMP," PROSIDING : Seminar Nasional Fisika Dan Pendidikan Fisika 6, $\begin{array}{llll}\text { no. } & 6 & \text { (September } & 12,\end{array}$ http://www.jurnal.fkip.uns.ac.id/index.php/prosfis1/article/view/7857.

3 I. Wayan Santyasa, "Metode Penelitian Pengembangan Dan Teori Pengembangan Modul," Makalah Disampaikan Dalam Pelatihan Bagi Guru-Guru Dan Dosen Di Nusa Penida Klungkung, 2009. 
Bahan ajar yang baik adalah bahan ajar yang dapat mengakomodir kemampuan yang akan dikembangkan. Oleh karena itu strutkur penyajian bahan ajar harus mengikuti indikator dari kemampuan yang akan dikembangkan. Misalkan jika fokus utama pembelajaran adalah untuk meningkatkan kemampuan pemecahan masalah maka bahan ajar haruslah disajikan berdasarkan indikator kemampuan pemecahan masalah dalam hal ini bahan ajar berpikir kritis dengan mengoptimalkan kemampuan berpikir tingkat tinggi mahasiswa atau Higher Order Thinking Skills (HOTS).

Kemampuan mahasiswa dalam berpikir kritis dan berpikir kreatif menjadi salah satu indikator kemampuan berpikir tingkat tinggi ${ }^{4}$. Berpikir kritis merupakan seni menganalisis dan mengevaluasi pemikiran dengan maksud untuk memperbaikinya. Seseorang yang memiliki kemampuan berpikir kritis akan memiliki kemampuan untuk bertanya dan merumuskannya dengan jelas dan tepat, berkomunikasi secara efektif dengan orang lain dalam mencari solusi untuk masalah yang kompleks ${ }^{5}$.

Berpikir kritis adalah kemampuan dan disposisi untuk melibatkan pengetahuan sebelumnya, penalaran matematis, dan menggunakan strategi kognitif dalam menggeneralisasi, membuktikan, atau mengevaluasi situasi matematis yang kurang dikenal dengan cara reflektif6. Orang yang berpikir kritis cenderung dapat mengevaluasi suatu masalah kemudian membuat kesimpulan berdasarkan fakta yang ada 7 .

Dalam keterampilan berpikir kritis perlu adanya pengulangan untuk melatihnya walaupun sebenarnya keterampilan ini sudah menjadi bagian dari kemapuan berpikir8. Latihan rutin yang dilakukan berdampak pada efisiensi dan berefek langung pada keterampilan berpikir yang telah dimiliki. Pada perkuliahan trigonometri proses berpikir yang paling utama adalah proses berpikir tingkat tinggi. Kemampuan berpikir kritis akan digunakan dalam kegiatan menganalisis soal, memahami setiap instruksi, mengaitkan pengetahuan dan sebagai alat yang sangat potensial untu melakukan penyaringan informasi. Kemampuan berpikir kritis dalam Higher Order Thinking Skills (HOTS) sudah dianggap sebagai kemampuan dasar yang

4 Weindy Pramita Ariandari, "Mengintegrasikan Higher Order Thinking Dalam Pembelajaran Creative Problem Solving," in Seminar Nasional Matematika Dan Pendidikan Matematika UNY, 2015, 492.

5 Linda Elder and Richard Paul, "Critical Thinking: Tools for Taking Charge of Your Learning and Your Life," 2011.

6 In Hi Abdullah, "Berpikir Kritis Matematik," Delta-Pi: Jurnal Matematika Dan Pendidikan Matematika 2, no. 1 (2016).

7 Pratiwi Dwijananti and D. Yulianti, "Pengembangan Kemampuan Berpikir Kritis Mahasiswa Melalui Pembelajaran Problem Based Instruction Pada Mata Kuliah Fisika Lingkungan," Jurnal Pendidikan Fisika Indonesia 6, no. 2 (2010): 112.

8 Retno Andriyani and Nisvu Nanda Saputra, "Kemampuan Berpikir Kritis Pada Perkuliahan Trigonometri," in Prosiding Seminar Nasional Pendidikan Matematika, vol. 1, 2019. 
sangat penting untuk dikuasai seperti halnya kemampuan membaca dan menulis.

Kemampuan berpikir kritis merupakan salah satu indikator kemampuan berpikir tingkat tinggi ${ }^{9}$.Semua komponen dalam berpikir tingkat tinggi merupaka bagian dari komponen kemampuan berpikir kritis. Dengan demikian, kemampuan berpikir kritis dapat membantu seseorang dalam kegiatan Berpikir tingkat tinggi.

Indikator berpikir kritis dibagi menjadi lima kelompok yaitu memberikan penjelasan sederhana, membangun keterampilan dasar, menyimpulkan, membuat penjelasan lebih lanjut dan menyusun taktik serta strategi penyelesaian. Indikator keterampilan berpikir kritis tersebut, kemudian dikembangkan menjadi lima kelompok yang dijelaskan dalam Tabel 110 .

Tabel 1. Indikator Berpikir Kritis

\begin{tabular}{|c|c|}
\hline Jenis Keterampilan & Indikator \\
\hline $\begin{array}{l}\text { Memberikan penjelasan } \\
\text { sederhana }\end{array}$ & $\begin{array}{l}\text { 1. Keterampilan memfokuskan pertanyaan } \\
\text { 2. Menganalisis argumen } \\
\text { 3. Bertanya dan menjawab pertanyaan }\end{array}$ \\
\hline $\begin{array}{l}\text { Membangun } \\
\text { keteranpilan dasar }\end{array}$ & $\begin{array}{l}\text { 1. menyesuaikan dengan sumber } \\
\text { 2. mengamati dan melaporkan hasil observasi }\end{array}$ \\
\hline Menyimpulkan & $\begin{array}{l}\text { 1. keterampilan mempertimbangkan } \\
\text { kesimpulan, } \\
\text { 2. melakukan generalisasi } \\
\text { 3. melakukan evaluasi. }\end{array}$ \\
\hline $\begin{array}{l}\text { Membuat penjelasan } \\
\text { lanjut }\end{array}$ & $\begin{array}{l}\text { 1. mengartikan istilah dan } \\
\text { 2. membuat definisi. }\end{array}$ \\
\hline $\begin{array}{lll}\text { Mengatur strategi dan } \\
\text { taktik }\end{array}$ & $\begin{array}{l}\text { 1. menentukan suatu tindakan dan } \\
\text { 2. berinteraksi dengan orang lain dan } \\
\text { berkomunikasi }\end{array}$ \\
\hline
\end{tabular}

Ada 3 tingkatan pembelajaran dalam ranah kognitif pada taksonomi Bloom yang direvisi oleh Anderson dan Krathwohl yaitu Lower Order Thinking Skill (LOTS), Medium Order Thinking Skill (MOTS), dan Higher Order Thinking Skill (HOTS). Pembagian masing-masing tingkatan tersebut dijelaskan pada Tabel $2^{11}$.

${ }^{9}$ Ariandari, "Mengintegrasikan Higher Order Thinking Dalam Pembelajaran Creative Problem Solving," 492.

10 Poppy Kamalia Devi, "Pengembangan Soal Higher Order Thinking Skill Dalam Pembelajaran IPA SMP/MTs," 4-5, accessed May 4, 2020, https://www.academia.edu/8337926/Pengembangan_Soal_HOTS_IPA_PENGEMBANGAN_SO AL_HIGHER_ORDER_THINKING_SKILL_DALAM_PEMBELAJARAN_IPA_SMP_MTs.

${ }^{11}$ Febi Ariani Saragih, "Penerapan Metode HOTS (Higher Order Thinking Skill) Dalam Pembelajaran Bahasa Jepang Di SMA," Journal of Japanese Language Education and Linguistics 3, no. 2 (2019): 151-52. 
81 Retno A \& Nisvu N S /Al-Khwarizmi: Jurnal Pendidikan Matematika dan Ilmu Pengetahuan Alam, Maret-2020, Vol.8, No.1, hal.77-86

Tabel 2. Tingkatan Pembelajaran dalam Ranah Kognitif menurut Anderson \& Krathwohl

\begin{tabular}{|c|c|c|c|}
\hline \multicolumn{3}{|c|}{ Proses Kognitif } & Definisi \\
\hline $\mathrm{C} 1$ & LOTS & Mengingat & $\begin{array}{l}\text { Mendapatkan pengetahuan yang } \\
\text { relevan melalui ingatan }\end{array}$ \\
\hline $\mathrm{C} 2$ & МOTS & Memahami & $\begin{array}{lcr}\text { Membangun arti dari proses } & \text { disan, } \\
\text { pembelajaran, } & \text { komunikasi } & \text { lisan, } \\
\text { informasi tertulis, dan gambar } & \end{array}$ \\
\hline $\mathrm{C} 3$ & S1010 & $\begin{array}{l}\text { Menerapkan } \\
\text { Mengaplikasi }\end{array}$ & $\begin{array}{l}\text { Menerapkan atau mengaplikasikan } \\
\text { prosedur di dalamsituasi yang tidak } \\
\text { biasa }\end{array}$ \\
\hline $\mathrm{C} 4$ & & Menganalisis & $\begin{array}{l}\text { Pemecahan materi ke dalam } \\
\text { beberapa bagian dan menentukan } \\
\text { bagaimana bagian-bagian tersebut } \\
\text { saling terhubung antarbagian dan ke } \\
\text { struktur atau tujuan keseluruhan }\end{array}$ \\
\hline $\mathrm{C} 5$ & HOTS & Menilai/Mengevaluasi & $\begin{array}{l}\text { Membuat pertimbangan berdasarkan } \\
\text { standar }\end{array}$ \\
\hline $\mathrm{C} 6$ & & Menkreasi/Mencipta & $\begin{array}{l}\text { Meletakkan beberapa unsur secara } \\
\text { bersamaan guna membentuk } \\
\text { keseluruan secara utuh atau } \\
\text { fungsional, menyusun kembali unsur- } \\
\text { unsur tersebut ke dalam pola atau } \\
\text { struktur baru }\end{array}$ \\
\hline
\end{tabular}

Pemecahan masalah merupakan basis utama dalam HOTS yang dibangun dari berpikir kritis dan kreatif. HOTS dibagi menjadi empat bagian yaitu pemecahan masalah, mengambil keputusan, berpikir krtis dan berpikir kreatif. Namun yang menjadi basis utama adalah berpikir kritis.

Bahan ajar atau modul ajar dimodifikasi, atau dikembangkan sendiri agar sesuai dengan kebutuhan dan tujuan pembelajaran ${ }^{12}$. Sementara itu, bahan ajar yang berientasi pada karakter dan HOTS sulit sekali ditemukan. Dengan demikian, pengembangan bahan ajar yang berorientasi karakter dan HOTS sangat penting untuk dilakukan. Pengembangan bahan ajar tersebut dapat dilakukan melalui penelitian pengembangan agar dapat dihasilkan produk yang valid, praktis dan efektif. Desiagi dkk telah mengembangkan bahan ajar berupa LKS untuk meningkatkan Higher Order Thinking Skills siswa salah satu SMK swasta di Slawi13. Anni Prastiwi dkk juga telah

12 Jailani Jailani, "Pengembangan Bahan Ajar Matematika Yang Berorientasi Pada Karakter Dan Higher Order Thinking Skill (HOTS)," PYTHAGORAS: Jurnal Pendidikan Matematika 9, no. 1 (2014): 45-59.

13 Desiagi Dwi Kristianingsih, Nanik Wijayati, and Sudarmin Sudarmin, "Pengembangan Lks Fisika Bermuatan Generik Sains Untuk Meningkatkan Higher Order Thinking (HOTS) Siswa," Journal of Innovative Science Education 5, no. 1 (June 20, 2016): 73-82. 
mengembangkan modul fisika berbasis masalah untuk meningkatkan High Order Thinking Skills (HOTS) siswa ${ }^{14}$. Lebih lanjut Yulia Dewi Puspitasari dan Triana Wuri Cahyanti mengembangkan modul berbasis scientific untuk meningkatkan Higher Order Thinking Skill (HOTS) mahasiswa15. Pada penelitian Saputra (2019) sudah dilakukan penelitian pengembangan bahan ajar berpikir kritis dan hasil dari penelitian tersebut disimpulkan bahwa bahan ajar sudah dalam kategori layak ${ }^{16}$. Artikel ini merupakan pengembangan dari penelitian tersebut dengan tujuan untuk mengoptimalkan kemampuan Higher Order Thinking Skill Mahasiswa Semester awal melalui penggunaan bahan ajar berpikir kritis.

\section{Metode}

Jenis penelitian ini adalah penelitian tindakan kelas, karena dalam penelitian ini akan menggambarkan bagaimana suatu bahan ajar yang digunakan dapat digunakan untuk mengoptimalkan kemampuan Higher Order Thinking Skill pada mahasiswa semester awal. Subjek dalam penelitian ini adalah mahasiswa semester I yang mengikuti Mata Kuliah Trigonometri di salah satu universitas swasta di Tangerang, dengan jumlah mahasiswa 25 orang yang terdiri dari 8 orang laki-laki dan 17 orang perempuan. Waktu penelitian pada semester ganjil tahun ajaran 2019/2020. Instrumen yang dalam penelitian ini adalah tes soal evaluasi yang digunakan untuk mengetahui kemampuan berpikir tingkat tinggi mahasiswa dan lembar observasi untuk melihat keterlaksanaan kegiatan pembelajaran. Kemampuan Higher Order Thinking Skill Mahasiswa Semester awal melalui penggunaan bahan ajar berpikir kritis dikatakan optimal apabila skor tes evaluasi mengalami peningkatan dari siklus sebelumnya. Skema yang digunakan dalam penlitian ini mengikuti skema di Gambar 1.

14 Sriyono Anni Prastiwi, "Pengembangan Modul Fisika Berbasis Masalah Untuk Meningkatkan High Order Thinking Skills (HOTS) Siswa SMA," Radiasi: Jurnal Berkala Pendidikan Fisika 9, no. 1 (September 19, 2016): 1-6.

15 Yulia Dewi Puspitasari and Triana Wuri Cahyanti, "Pengembangan Modul Fisika Dasar Berbasis Scientific Untuk Meningkatkan Higher Order Thinking Skill (HOTS)," Jurnal Materi Dan Pembelajaran Fisika 8, no. 2 (September 15, 2018): 65-72, https://doi.org/10.20961/jmpf.v8i2.28448.

16 Nisvu Nanda Saputra and Retno Andriyani, "Pengembangan Bahan Ajar Berbasis Berpikir Kritis Berbantuan Geogebra," in Prosiding Seminar Nasional Pendidikan Matematika, vol. 1, 2019. 
83 Retno A \& Nisvu N S /Al-Khwarizmi: Jurnal Pendidikan Matematika dan Ilmu Pengetahuan Alam, Maret-2020, Vol.8, No.1, hal.77-86

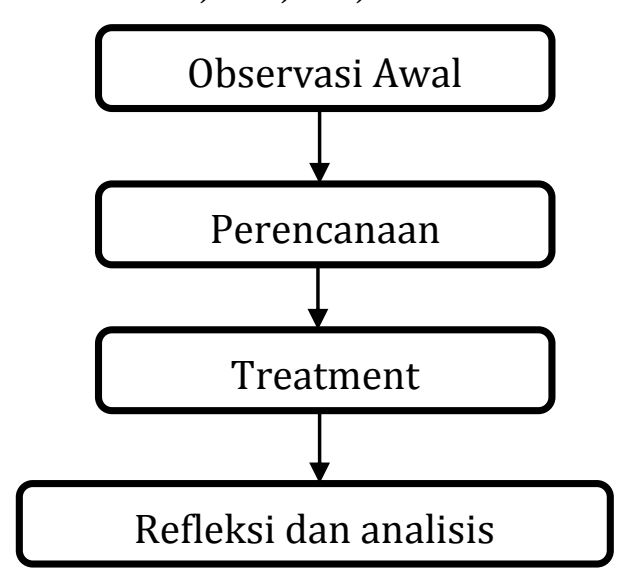

Gambar 1: Skema Penelitian

Kriteria keterlaksanaan kegiatan pembelajaran yang digunakan dalam penelitian ini dikategorikan dalam 5 kategori seperti Tabel 3.

Tabel 3. Kriteria Keterlaksanaan Kegiatan Pembelajaran

\begin{tabular}{cc}
\hline Interval & Deskripsi \\
\hline $0<\mathrm{x} \leq 20$ & Sangat Kurang \\
\hline $20<\mathrm{x} \leq 45$ & Kurang \\
\hline $45<\mathrm{x} \leq 60$ & Cukup \\
\hline $60<\mathrm{x} \leq 85$ & Baik \\
\hline
\end{tabular}

\section{Hasil dan Diskusi}

Tahap awal penelitian adalah melakukan observasi awal kepada mahasiswa semester awal untuk mengetahui permasalahan dan kebutuhan pembelajaran. Observasi awal dilakukan dengan pemberian soal HOTS kepada mahasiswa semester awal. Hasil yang diperoleh menunjukan bahwa masih rendahnya kemampuan mahasiswa dalam menyelesaikan soal HOTS.

Pelaksanaan pembelajaraan dengan menggunakan bahan ajar berpikir kritis dilaksanakan dalam 6 pertemuan masing-masing dibagi menjadi 3 pertemuan setelah dilaksakan dua pertemuan pada pertemuan ketiga dilakukan tes yang masing-masing bagi menjadi 2 siklus, pemberian tes untuk melihat peningkatan kemampuan higher order thinking skills mahasiswa semester awal. Pada setiap tindakan yang dilakukan akan dilihat keterlaksanaan tahap pembelajaran yang berdasarkan kepada berpikir kritis.

Hasil pengamatan terhadap keterlaksanaan kegiatan pembelajaran yang dilakukan dapat dilihat pada Tabel 4. Berdasarkan Tabel 4, terjadi peningkatan skor keterlaksanaan kegiatan pembelajaran dari siklus I ke siklus II. Peningkatan ini menyebabkan peningkatan kegiatan partisipasi atau keaktifan mahasiswa dalam proses pembelajaran. 
84 Retno A \& Nisvu N S /Al-Khwarizmi: Jurnal Pendidikan Matematika dan Ilmu Pengetahuan Alam, Maret-2020, Vol.8, No.1, hal.77-86

Tabel 4. Keterlaksanaan Kegiatan Pembelajaran

\begin{tabular}{ccc}
\hline & & \multicolumn{1}{c}{ Skor } \\
\hline \multirow{3}{*}{ Siklus I } & Rata-rata & 3,35 \\
\cline { 2 - 3 } & Persentase & $84,60 \%$ \\
\cline { 2 - 3 } & Kategori & Baik \\
\hline \multirow{3}{*}{ Siklus II } & Rata-rata & 3,85 \\
\cline { 2 - 3 } & Persentase & $96,35 \%$ \\
\cline { 2 - 3 } & Kategori & Sangat Baik \\
\hline
\end{tabular}

Pelakasanaan pembelajaran melalui penggunaan bahan ajar berpikir kritis ini adalah untuk mengoptimalkan kemampuan HOTS mahasiswa. Untuk melihat peningkatan tersebut dilakukan tes setiap akhir siklus yang dilaksanakan yaitu pada pertemuan ketiga setelah melakukan kegiatan pembelajaran, berikut hasil peningkatan kemampuan HOTS mahasiswa setelah melakukan pembelajaran dengan menggunakan bahan ajar berpikir kritis.

Tabel 5. Peningkatan Kemampuan HOTS Mahasiswa

\begin{tabular}{ccc}
\hline & & Skor \\
\hline \multirow{3}{*}{ Siklus I } & Nilai $\geq 75$ & 15 \\
\cline { 2 - 3 } & Persentase & $60 \%$ \\
\cline { 2 - 3 } & kategori & Cukup \\
\hline \multirow{3}{*}{ Siklus II } & Nilai $\geq 75$ & 23 \\
\cline { 2 - 3 } & Persentase & $92 \%$ \\
\cline { 2 - 3 } & kategori & Sangat Baik \\
\hline
\end{tabular}

Berdasarkan Tabel 5, terlihat bahwa ada peningkatan kemampuan HOTS mahasiswa semester awal setelah dilakukan pembelajaran atau perkuliahan dengan menggunakan bahan ajar berpikir kritis. Penggunaan modul untuk mengoptimalkan HOTS ini sejalan dengan hasil penelitian Ngurah Mahendra Dinatha ${ }^{17}$ dan Gita Erlangga Kurniawan ${ }^{18}$. Dengan demikian kemampuan Higher Order Thinking Skill Mahasiswa semester awal dapat dioptimalkan dengan penggunaan bahan ajar berpikir kritis.

17 Ngurah Mahendra Dinatha and Maria Yuliana Kua, "Pengembangan Modul Praktikum Digital Berbasis Nature of Science (NoS) Untuk Meningkatkan Higher Order Thinking Skill (HOTS)," Journal of Education Technology 3, no. 4 (November 30, 2019): 293300, https://doi.org/10.23887/jet.v3i4.22500.

18 Gita Erlangga Kurniawan, "Pengembangan Modul Pembelajaran Berbasis Model Problem Solving Untuk Meningkatkan High Order Thinking Skill Pada Pelajaran IPA Pokok Bahasan Fluida Pelajaran IPAPokok Bahasan Fluida Statis Siswa Kelas VIII SMPN 7 Cirebon," Jurnal Mangifera Edu 3, no. 1 (July 30, 2018): 62-71, https://doi.org/10.31943/mangiferaedu.v3i1.19. 


\section{Kesimpulan}

Berdasarkan hasil penelitian yang sudah diuraikan sebelumnya dapat disimpulkan bahwa penggunaan bahan ajar berpikir kritis dapat mengoptimalkan kemampuan Higher Order Thinking Skills (HOTS) mahasiswa awal pada mata kuliah trigonometri. Hal ini berdasarkan peningkatan nilai rata-rata mahasiswa dari siklus I ke Siklus II. Saran untuk penelitian selanjutnya adalah melengkapi penelitian dengan melakukan wawancara agar proses berpikir mahasiswa yang melakukan berpikir tingkat tinggi lebih dapat dideskripsikan secara komprehensif.

\section{Daftar Pustaka}

Abdullah, In Hi. "Berpikir Kritis Matematik." Delta-Pi: Jurnal Matematika Dan Pendidikan Matematika 2, no. 1 (2016).

Andriyani, Retno, and Nisvu Nanda Saputra. "Kemampuan Berpikir Kritis Pada Perkuliahan Trigonometri." In Prosiding Seminar Nasional Pendidikan Matematika, Vol. 1, 2019.

Anni Prastiwi, Sriyono. "Pengembangan Modul Fisika Berbasis Masalah Untuk Meningkatkan High Order Thinking Skills (HOTS) Siswa SMA." Radiasi: Jurnal Berkala Pendidikan Fisika 9, no. 1 (September 19, 2016): 1-6.

Ariandari, Weindy Pramita. "Mengintegrasikan Higher Order Thinking Dalam Pembelajaran Creative Problem Solving." In Seminar Nasional Matematika Dan Pendidikan Matematika UNY, 2015.

Devi, Poppy Kamalia. "Pengembangan Soal Higher Order Thinking Skill Dalam Pembelajaran IPA SMP/MTs." Accessed May 4, 2020. https://www.academia.edu/8337926/Pengembangan_Soal_HOTS_IPA_ PENGEMBANGAN_SOAL_HIGHER_ORDER_THINKING_SKILL_DALAM_PE MBELAJARAN_IPA_SMP_MTs.

Dinatha, Ngurah Mahendra, and Maria Yuliana Kua. "Pengembangan Modul Praktikum Digital Berbasis Nature of Science (NoS) Untuk Meningkatkan Higher Order Thinking Skill (HOTS)." Journal of Education Technology 3, no. 4 (November 30, 2019): 293-300. https://doi.org/10.23887/jet.v3i4.22500.

Dwijananti, Pratiwi, and D. Yulianti. "Pengembangan Kemampuan Berpikir Kritis Mahasiswa Melalui Pembelajaran Problem Based Instruction Pada Mata Kuliah Fisika Lingkungan." Jurnal Pendidikan Fisika Indonesia 6, no. 2 (2010).

Elder, Linda, and Richard Paul. "Critical Thinking: Tools for Taking Charge of Your Learning and Your Life," 2011.

Jailani, Jailani. "Pengembangan Bahan Ajar Matematika Yang Berorientasi Pada Karakter Dan Higher Order Thinking Skill (HOTS)." PYTHAGORAS: Jurnal Pendidikan Matematika 9, no. 1 (2014): 45-59.

Kristianingsih, Desiagi Dwi, Nanik Wijayati, and Sudarmin Sudarmin. "Pengembangan Lks Fisika Bermuatan Generik Sains Untuk 
86 Retno A \& Nisvu N S /Al-Khwarizmi: Jurnal Pendidikan Matematika dan Ilmu Pengetahuan Alam, Maret-2020, Vol.8, No.1, hal.77-86

Meningkatkan Higher Order Thinking (HOTS) Siswa." Journal of Innovative Science Education 5, no. 1 (June 20, 2016): 73-82.

Kurniawan, Gita Erlangga. "Pengembangan Modul Pembelajaran Berbasis Model Problem Solving Untuk Meningkatkan High Order Thinking Skill Pada Pelajaran IPA Pokok Bahasan Fluida Pelajaran IPAPokok Bahasan Fluida Statis Siswa Kelas VIII SMPN 7 Cirebon." Jurnal Mangifera Edu 3, no. 1 (July $30, \quad$ 2018): https://doi.org/10.31943/mangiferaedu.v3i1.19.

Lestari, Dita Puja. "Pengembangan Bahan Ajar Matematika Dengan Pendekatan Scientific Untuk Meningkatkan Kemampuan Berpikir Kritis Matematis Siswa SMA Negeri 1 Bandar Pulau." AXIOM: Jurnal Pendidikan Dan Matematika 7, no. 2 (2018).

Puspitasari, Yulia Dewi, and Triana Wuri Cahyanti. "Pengembangan Modul Fisika Dasar Berbasis Scientific Untuk Meningkatkan Higher Order Thinking Skill (HOTS)." Jurnal Materi Dan Pembelajaran Fisika 8, no. 2 (September 15, 2018): 65-72. https://doi.org/10.20961/jmpf.v8i2.28448.

R, Nurmala, and Alfian Mucti. "Efektivitas Penggunaan LKM Berbasis Hots (Higher Order Thinking Skills) Terhadap Hasil Belajar Mahasiswa Pendidikan Matematika." Journal of Honai Math 2, no. 2 (August 13, 2019): 117-28. https://doi.org/10.30862/jhm.v2i2.67.

Sakti, Indra. "Implementasi Model Perangkat Pembelajaran Berorientasi Hots (High Order Thinking Skills) Dan Pendidikan Karakter Melalui PBL (Problem Based Learning) Pada Mata Kuliah Fisika Dasar." PROSIDING SEMINAR NASIONAL FISIKA (E-JOURNAL) 8 (December 31, 2019): SNF2019-PE-389-400. https://doi.org/10.21009/03.SNF2019.01.PE.50.

Santyasa, I. Wayan. "Metode Penelitian Pengembangan Dan Teori Pengembangan Modul." Makalah Disampaikan Dalam Pelatihan Bagi Guru-Guru Dan Dosen Di Nusa Penida Klungkung, 2009.

Saputra, Nisvu Nanda, and Retno Andriyani. "Pengembangan Bahan Ajar Berbasis Berpikir Kritis Berbantuan Geogebra." In Prosiding Seminar Nasional Pendidikan Matematika, Vol. 1, 2019.

Saragih, Febi Ariani. "Penerapan Metode HOTS (Higher Order Thinking Skill) Dalam Pembelajaran Bahasa Jepang Di SMA." Journal of Japanese Language Education and Linguistics 3, no. 2 (2019).

Wahyuni, Sri. "Pengembangan Bahan Ajar IPA Untuk Meningkatkan Kemampuan Berpikir Kritis Siswa SMP." PROSIDING : Seminar Nasional Fisika Dan Pendidikan Fisika 6, no. 6 (September 12, 2015). http://www.jurnal.fkip.uns.ac.id/index.php/prosfis1/article/view/785 7. 